\title{
EGFR NM_005228.3:C.1474A>C
}

National Cancer Institute

\section{Source}

National Cancer Institute. EGFR NM 005228.3:C.1474A>C. NCI Thesaurus. Code C135729.

A nucleotide substitution at position 1474 of the coding sequence of the EGFR gene where adenine has been mutated to cytosine. 